doi: $10.51741 / \mathrm{sd} .2021 .60 .2 .181-186$

Hubert Höllmüller

\title{
An Austrian social work project in Western Sahara
}

Western Sahara is a territory in northwest Africa, bordered by Morocco, Algeria, Mauritania, and the Atlantic Ocean. In 1963, the United Nations asked Spain as the colonial power of Western Sahara, to decolonize the territory. But Spain did not answer this call, instead it handed the colony to the neighboring countries Morocco and Mauretania. In reaction, the Sahrawi people proclaimed the Democratic Arab Republic of Western Sahara or DARS. After the invasion of Morocco in the north and of Mauretania in the south, part of the people fled to Algeria and erected several refugee camps that exist to this day.

According to Dreven, Poprask in Ramšak (2019), a military conflict ensued. Mauretania retreated in 1985 and Morocco took over this area and succeeded in permanently occupying about $80 \%$ of the Western Sahara, and the DARS was left with around 20\%. Morocco brought in several hundred thousand of its citizens. To cut off the $20 \%$ rest of Western Sahara, a $2700 \mathrm{~km}$ long wall known as "the Berm," surrounded by millions of land mines was built. In 1991, the United Nations brokered a ceasefire agreement and established a peacekeeping mission, the MINURSO, which has been monitoring the ceasefire and the buffer zone along the Berm for 29 years, but without any mandate to monitor the human rights situation in the occupied area. A referendum should have been carried out, but it hasn't happened. The UN finished the register of voters, but Morocco refuses to accept it.

Western Sahara is to this day the largest territory on the UN's list of Non-Self-Governing Territories by both land area and population. The Western Saharan conflict is fundamentally a question of decolonization: an anomaly in an otherwise successful process of the decolonization of Africa. The territory is therefore often referred to as "the last African colony".

The Sahrawi refugee camps were first established in this harsh and inhospitable desert plain during 1975 and 1976 by Sahrawi refugees fleeing from advancing Moroccan forces. The land was offered freely by the Algerian government, but it is subject to scorching temperatures, frequent sandstorms, and lack of vegetation. It is often referred to as "the Devil's Garden." The last official counting of the UN (in 2019) showed up a figure of 173.000 people living permanently in the camps.

As one of the last unresolved decolonization issues on Earth, Western Sahara should be one of the international community's most urgent priorities. A situation of refuge and exile, imagined to be temporary, has in this case become a permanent status quo. This frozen conflict has an increasing 
potential of again turning violent, as frustration and hopelessness take root in Sahrawi refugee communities, especially among the youth. In a world of growing instabilities, preventing such an escalation in favor of peaceful means of conflict resolution should be in everyone's best interest. (Dreven, Poprask in Ramšak, 2019, p. 82 ff)

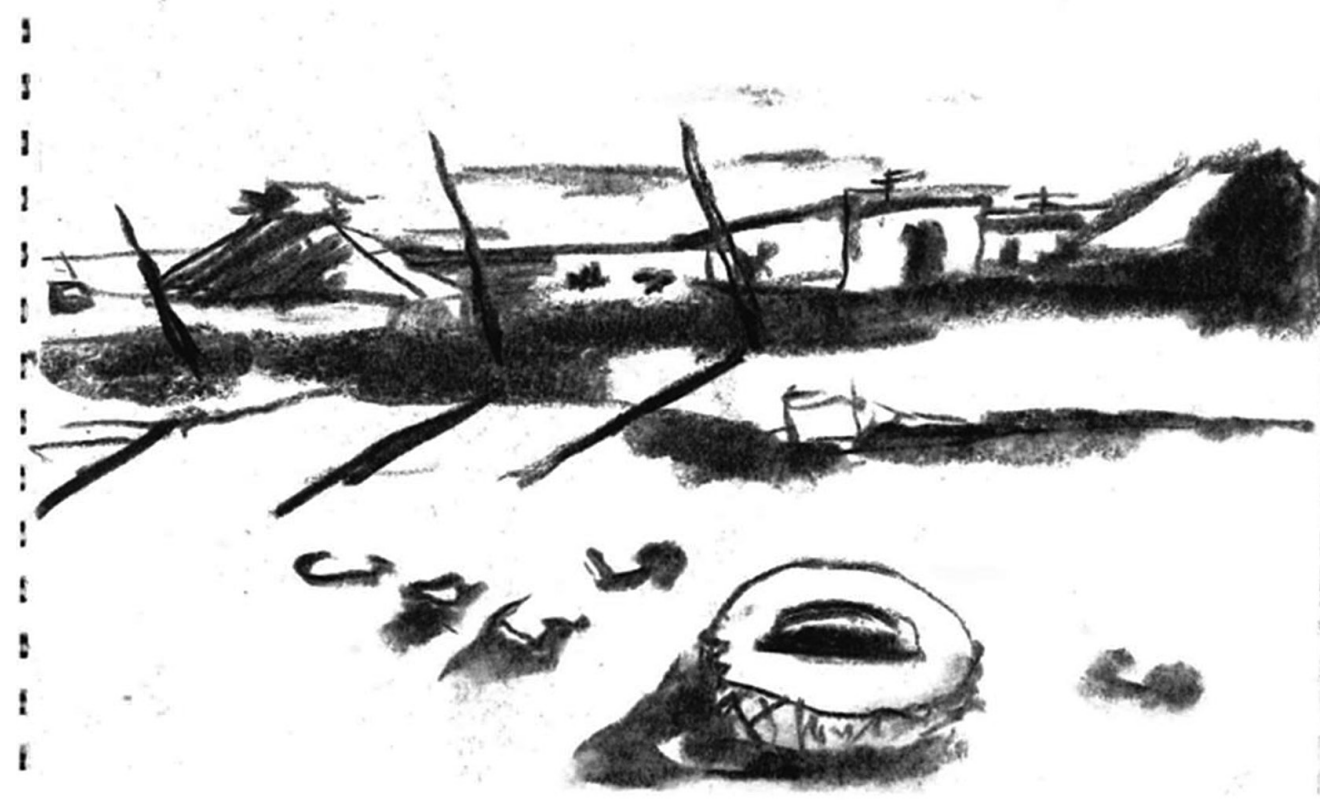

Charcoal drawing of the refugee camp by E. Sorgo.

The conflict could be solved easily by the European Union. All the big ex-colonial countries in Europe could put an end to the last African colony. But the official France and Spain have good ties with Morocco, so instead of putting political and economic pressure they are intervening against any diplomatic efforts to bring the conflict to public's awareness. One of the last examples is the Austrian Parliament, where representatives of all parties in March 2018 proposed a motion for a resolution on human rights monitoring of MINURSO (the UN mission for the Western Sahara) in the occupied territory and for the referendum referring to all UN resolutions, but after diplomatic interventions the parliament didn't proclaim anything.

The conflict of Western Sahara contains some ingredients to be a good practice example for refugee work in Northern Africa: 173,600 self-organized refugees live in their camps near Tindouf in Algeria. They have established an educational system and a basic health system. Most of them don't want to go to Europe. Their religion is a moderate independent Islam and their state in exile strives for democratic values. But the Sahrawi people have the big misfortune of having $80 \%$ of their territory, now under Moroccan rule, full of natural resources and with rich fishing grounds. In their resistance to Morocco, they were successful enough to be offered a ceasefire in 1991 and a referendum on legal status of Western Sahara. Friedhard Teuffel (2018), a journalist, explains why this Western Sahara conflict is ignored in European discourses: 
Based on UN resolutions, there should have been a referendum on the status of Western Sahara, which could bring back the territory to the Sahrawi. But it hasn't happened so far. And from where should the pressure come to organize it? There is little the Sahrawi can do. Their situation is severe, but not catastrophic. Most of them depend on food donations of the world food program. Diseases and diabetes are increasing. In the refugee camps, tents were transformed into mud huts. [...] Morocco on the other hand has made its profit out of the natural resources of the Western Sahara and settled it with Moroccans. The referendum is inhibited by the question who would be allowed to vote. [...] Morocco can do what it wants with the Western Sahara, as nobody wants to start a head-to-head contest with Morocco because of some 160,000 nomads. Recently Morocco has got a new fishery agreement with the EU, including the coasts of Western Sahara, even though the European Court of Justice decided that any fishery agreement has to exclude Western Sahara. The EU Commission does not seem to be bothered. A crucial factor is, that Morocco is a passing country for refugees on their way to Europe. This strengthens its position, despite reports that this north African state deports refugees into the desert. So the Sahrawi remain in their refugee settlements, which exist for too long to be provisional, but should not be permanent.

In 2012, the Western Sahara Government founded the University of Tifariti, as the first university located in refugee camps, and the rector Jatari Hamudi was invited by the Carinthian University of Applied Sciences (CUAS) to sign a cooperation agreement. With this contract, CUAS applied for an Erasmus program and the Austrian National Agency accepted the argument that as the refugee camps are located in Algeria and Algeria is one of the countries eligible in the program, an academic exchange can be carried out. In 2017/2018 students and professors from the camps and from Carinthia visited each other. After this first step, the Carinthian regional government funded a project, where young

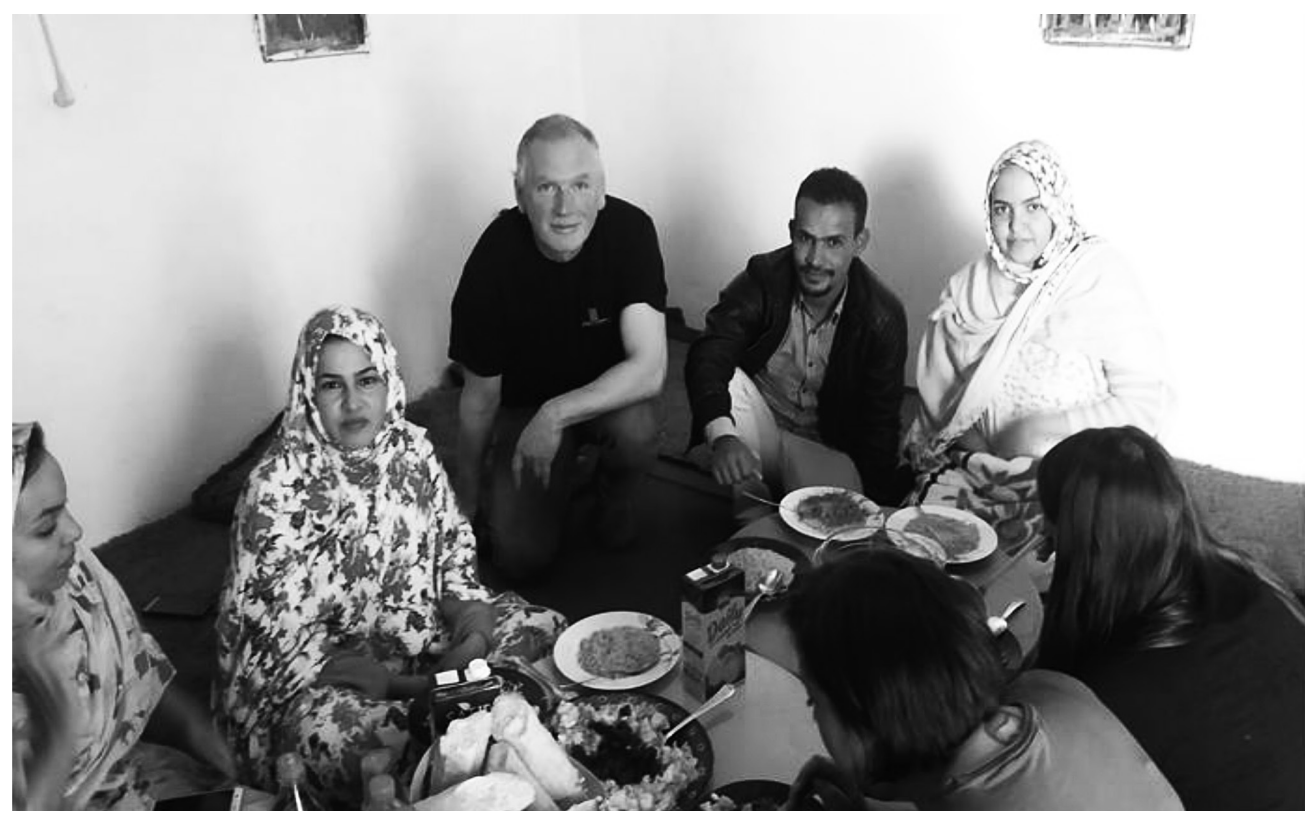

Photo 1: International meeting with Hubert Höllmüller (in the middle). 
Sahrawi academics should develop research designs related to the camps and social issues there. Following the proposals of Sahrawi colleagues, the University of Tifariti made a call for applicants for four one-year scholarships for young female academics in the field of social sciences.

The first hearing was organized in Boujdour in June 2018, where two students were chosen, and the second hearing in January 2019, where the other two students were selected. In January the first seminar started on scientific research principles in the camps and the second took place in June 2019 also in the camps about the first research ideas.

Two of the young academics were invited to Carinthia and to the partner universities in Ljubljana and Cologne, and in February 2020 the last workshop took place in the camps. During the year, there were ongoing contacts via skype, email and WhatsApp.

The names of researchers: Khadija Mumu, Nuna Mohamed, Raaba Ahmed Ali, Salamo Omar, Rhageb Ahmed Baba, Majidi Mohamed Bouzid (coordinator), Fatimetu Sidi Mohamed (Education Professor at the University of Tifariti)

Major research topics which were discussed by Sahrawi researchers were the following:

- political attitudes of Sahrawi youth in the refugee camps,

- danger of whitening cosmetics for young Sahrawi women,

- relation of children to their fathers during parental divorce,

- mute and deaf children in the camps,

- ideas of war invalids in the Polisario center for war invalids,

- women and men in wheelchairs in the camps doing sports,

- wishes and worries of kindergarten teachers, educated in Austria, working and living in the refugee camps,

- day nursery for children between 0 and 2,

- what makes young Sahrawis disconnect with the refugee society and political authorities.

Researcher Salamo Omar came to the first workshop with an elaborated questionnaire for Sahrawi youth regarding their democratic values. He designed questions to assess: do they respect freedom of opinion and thinking; do they respect others regardless of intellectual extremism and affiliation; do they respect others regardless of their religious/nonreligious orientation; do they respect others regardless of their sexual orientation; do they accept the opinions opposing their opinion and discuss them; do they believe in the diversity of political and cultural ideas; what do they think of violence; and does democracy conflict with the values and customs of their society.

Researcher Raaba Ahmed Ali worked on this research topic very independently. She wanted to make young Sahrawi women question the ideals of pale skin as an expression of beauty and to alert women about the risks of using non-medical bleaching creams. After carrying out 100 interviews, she found out that there is no regulation by the authorities to avoid the selling of harmful cosmetics. Most young Sahrawi women confirm that pale skin is regarded as beautiful, but only a smaller part agrees with this statement. 


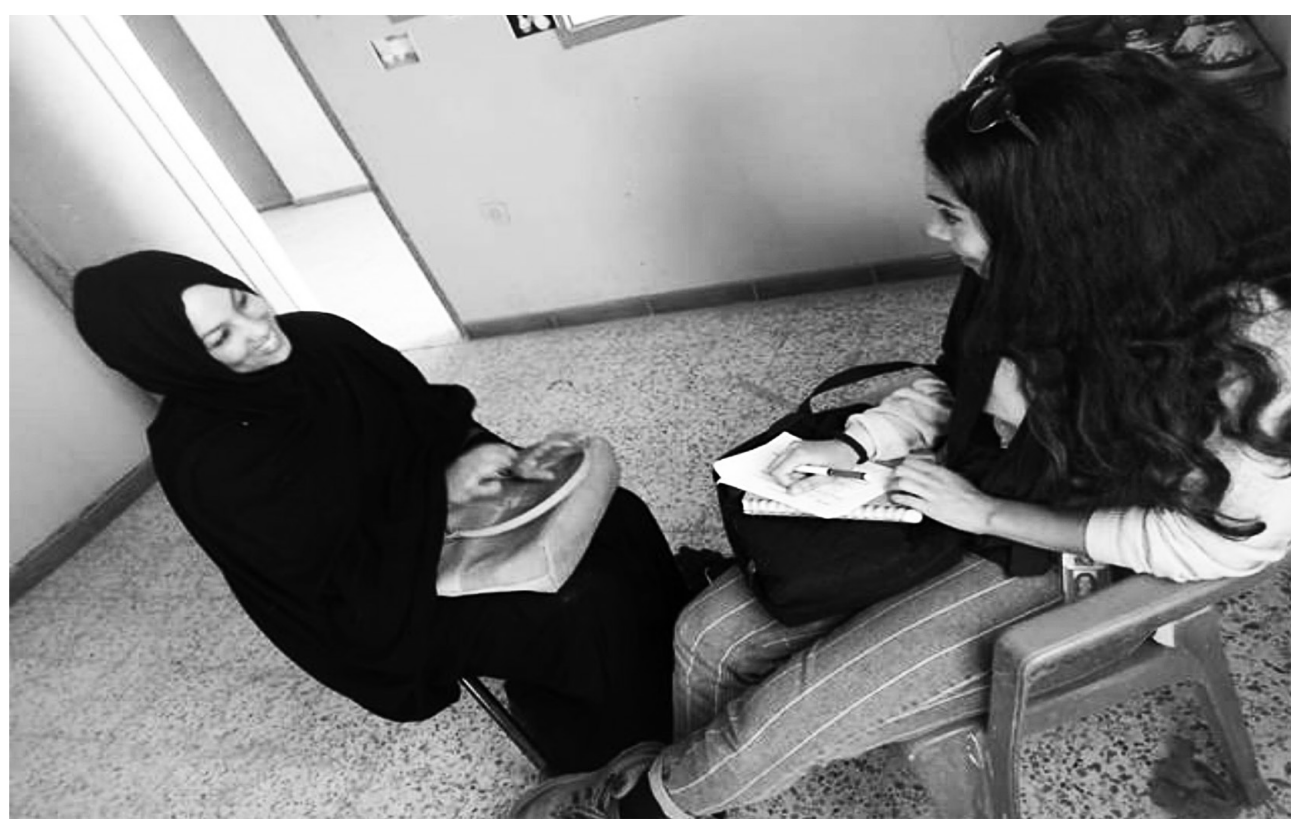

Photo 2: Interviewing.

Raaba Ahmed Ali also worked on a second research question about family disintegration. The Sahrawi society is facing the phenomenon of family disintegration due to unstable situation and the state of wars. Her research goals were to know the effects and dimensions of family disintegration, to understand what the causes of family disintegration are - social, cultural, political or religious, and is family disintegration linked to the enormous changes that have affected social life in Sahrawi society?

Austrian students Lisa Bebek and Franziska Syme who spent their Erasmus semester at the University of Tifariti, carried out an action research in the Sahrawi refugee camp focusing on the kindergarten educators trained in Austria. The main findings from their report: there is a big need of meetings and exchange among the kindergarten educators, which has not been met. The educators complain about the new standard from the Algerian Ministry of Education that kindergarten should be run like a pre-school where children are not allowed to play but instead should learn how to write and read and calculate in a very strict structure. The educators who were partly trained in Austria, were taught there that playing is the central element of any kindergarten program. They learnt the importance of a good day-structure and that there has to be a balance between activity and recovery.

Lisa Bebek wrote in her personal protocol the following:

We realized very soon that the women had the need to talk and to tell us about their worries. So we decided to start every workshop with small group discussions where they had to write down their biggest worries about their everyday work with the children. Thus we were informed that the curriculum, which was elaborated by Austrian professionals, was abolished and that since three years the curriculum of the Algerian kindergarten-system, which is much more a curriculum for primary school, has 
to be executed. The women really were desperate and felt left alone. They also were concerned that the now missing physical activities could harm the children and that the strict learning could inhibit the development of social competences.

As representatives of an Austrian university, we learnt much more during this project than the young researchers from the refugee camps. From a sociological point of view, the life in the refugee camps shows a kind of unnormal normality as there are housings, roads, taxis, schools, shops and also bureaucracy and social networks crossing tribal structures. Improvements on their social and political structures in the reality of the refugee camps should be addressed.

It has been shown that the critical inner perspective on the Sahrawi refugee society exists and that the young generation of the scientific community there knows exactly where the main problems lie and how they can - and have to - be made visible by research. Three of the researchers are actually in Europe to follow their individual plans and dreams - a big loss for the Sahrawi scientific community. Hopefully, opportunities might pop up for them to go back to the camps to work on the central research question: what are the reasons for the young generation to distance itself from the structures of the Sahrawi society and how to prevent it so that the Sahrawi refugee society will not disintegrate?

Luckily, in July 2020, we got the information that another Erasmus+ program with the University of Tifariti has been accepted by the Austrian National Agency.

\section{Sources}

Dreven, S., Poprask, C., \& Ramšak, R. (2019). The everyday reality of Saharawi people in the exile. In H. Höllmüller et al., Erasmus goes Westsahara. (pp. 82-126). Klagenfurt/Celovec: Drava.

Teuffel, F. (2018). Die vergessenen Flüchtlinge der Saharaui. Der Tagespiegel, 12 September 2018. Retrieved on 14 December 2020 from https://www.tagesspiegel.de/politik/migration-in-afrika-die-vergessenen-fluechtlinge-der-saharaui/23015262.html 